\title{
A influência dos estilos de liderança sobre os resultados de treinamento
}

\section{The influence of leadership styles of the results of training}

\section{La influencia de los estilos de liderazgo de los resultados de la formación}

\author{
Neilda de Souza Oliveira da Silva* \\ Universidade Salgado de Oliveira - Universo, Niterói, Rio de Janeiro, Brasil
}

\section{Luciana Mourão**}

Universidade Salgado de Oliveira - Universo, Niterói, Rio de Janeiro, Brasil

\begin{abstract}
RESUMO
Considerando que o treinamento se relaciona com os demais subsistemas de gestão de pessoas e que esta área está interligada ao comportamento humano no trabalho, o objetivo do presente estudo foi verificar se a percepção do estilo de liderança dos chefes influencia no impacto do treinamento no desempenho dos subordinados, tendo o suporte à transferência como variável controle. Para alcançar esse objetivo, foi realizada pesquisa com 264 empregados de uma indústria de refrigerante situada no Estado do Rio de Janeiro. O referencial teórico que embasou a pesquisa foi o da Liderança Situacional proposta por Hersey e Blanchard. O suporte à transferência foi incluído no modelo como variável controle, por ser a variável que mais explica o impacto do treinamento. Os resultados apontam correlação positiva do impacto do treinamento no trabalho com ambos os estilos de liderança - voltado para as pessoas e voltado para a produção. Porém, somente a percepção de liderança preocupada com a produção e o suporte à transferência constaram como preditores do impacto do treinamento. Assim, é esperado maior impacto dos eventos de capacitação no desempenho no trabalho quando os egressos de treinamentos são liderados por gerentes focados na produção e quando recebem o suporte psicossocial necessário para aplicação das competências adquiridas.
\end{abstract}

Palavras-chave: estilos de liderança, impacto do treinamento no trabalho, suporte à transferência de treinamento.

\begin{abstract}
Whereas the training is related to other subsystems of personnel management and that this area is linked to human behavior at work, this study intends to verify that the perceived leadership style of leaders influence the impact of training on performance of subordinates when the transfer support is a control variable. To achieve this goal, we performed a research with 264 employees in a soft drinks industry located in Rio de Janeiro (Brazil). The theoretical framework that supports the research of leadership was the proposal of Situational Leadership by Hersey and
\end{abstract}


Blanchard. As a control variable was included to support the transfer, since there are consistent indications of their influence on the impact of training. The survey results showed significant and positive correlation between the leadership's concern with people and the leadership's concern with the production and the impact of training on the job. However, only the perception of leadership concerned with the production and support the transfer of training are predictors of the impact of training. Thus, it is expected greater impact of training events in the job performance when people are led by managers focused on production and when they receive the necessary psychosocial support for application of acquired skills.

Keywords: leadership styles, training impact at work, support the transfer of training.

\section{RESUMEN}

Mientras que la formación se refiere a los otros subsistemas de la gestión de personas y su relación con el comportamiento humano en el trabajo, el objetivo de este estudio fue verificar que el estilo de liderazgo percibido de los principales factores que influyen en el impacto de la capacitación en el desempeño de los subordinados cuando el soporte de transferencia es una variable de control. Para lograr este objetivo, se realizó una investigación con 264 trabajadores en una industria de refrigerante ubicada en el Rio de Janeiro (Brasil). El marco teórico que basa la investigación fue el Liderazgo Situacional propuesto por Hersey y Blanchard. El soporte de transferencia se incluyó en el modelo como una variable de control, ya que es la variable que más explican el impacto de la capacitación. Los resultados indican una correlación positiva del impacto de la capacitación en el trabajo con los dos estilos de liderazgo - preocupado por las personas y preocupado por la producción. Sin embargo, sólo la percepción de liderazgo se ocupa de la producción y lo apoyo a la transferencia de la formación son predictores del impacto de la formación. Por lo tanto, se espera un mayor impacto de los eventos de capacitación en el desempeño en el trabajo cuando las personas son dirigidas por gerentes se centró en la producción y cuando reciben el apoyo psicosocial necesario para la aplicación de las competencias adquiridas.

Palabras clave: estilos de liderazgo, impacto de la capacitación en el trabajo, apoyar la transferencia de la formación.

\section{Introdução}

A competitividade da economia mundial tem ampliado as exigências sobre as organizações e seus gestores, aumentando o interesse pela temática da liderança (Bryman, 1996). Apesar de ser um objeto de estudo antigo - Confúcio (500 AC) escreveu um dos primeiros tratados sobre liderança, a partir de escritos de Platão e César (AsSadeq \& Khoury, 2006) - o tema continua bastante pesquisado (Cherian \& Farouq, 2013; Garg \& Ramjee, 2013; Wu, 2014).

A presente pesquisa está centrada na influência da liderança sobre os resultados das ações educacionais no ambiente de trabalho. Os estudos sobre a aprendizagem humana no trabalho também remontam aos primórdios da civilização (Vargas, 1996), mas foi a partir da Segunda Guerra Mundial que a área ganhou maior 
importância (Pilati, 2006). Atualmente, observa-se um crescimento das pesquisas sobre o tema (Borges-Andrade, Zerbini, Abbad \& Mourão, 2013; Aguinis \& Kraiger, 2009; Griffin, 2012; Salas \& Cannon-Bowers, 2001).

Embora já tenham sido realizadas muitas pesquisas sobre o impacto do treinamento no trabalho, não se encontrou na literatura nenhuma pesquisa que relacione esta variável ao estilo de liderança. A relação entre essas variáveis é relevante porque com o enorme volume de investimentos na área de treinamento (Salas \& Cannon-Bowers, 2001; Mourão, Abbad \& Zerbini, 2014), seria muito útil identificar variáveis que predizem o impacto dessas ações no desempenho no trabalho (Pilati \& Borges-Andrade, 2004; Freitas \& Borges-Andrade, 2004). Nesse sentido, este estudo teve como objetivo verificar se a percepção do estilo de liderança dos chefes influencia no impacto do treinamento no desempenho dos subordinados, tendo o suporte à transferência como variável controle. A seguir é apresentada uma breve revisão de literatura sobre essas temáticas.

\subsection{Liderança em organizações de trabalho}

Uma discussão na literatura questiona se liderança e gerência/chefia são conceitos distintos. No Grid Gerencial, o próprio nome do modelo remete a "gerenciamento", no entanto, ao longo de sua descrição, Blake e Mouton (1964) apontam os "estilos de liderança" derivados da análise do Grid. Nesse sentido, os autores não fazem distinção entre os termos "liderança" e "gerente".

Melo (2004) ressalta que o estudo da liderança no campo do comportamento organizacional analisa 0 líder dentro das organizações e na sua relação com a sociedade, ou com outros grupos sociais, e explica que vem daí o fato de que a maioria dos estudos sobre liderança voltaram-se para a função gerencial. Na mesma linha, Reddin (1970) aponta para a semelhança entre líder e gerente. O autor afirma que "um líder não é, na verdade, um gerente no sentido formal. Ele é alguém que os outros consideram como principal responsável pela realização dos objetivos do grupo" (Reddin, 1970, p.23). Contudo, ele afirma que em seu livro usou o termo "gerente" em vez de "líder", mas que praticamente tudo se aplica tanto ao líder quanto ao gerente.

Há também outros trabalhos como o de Carneiro (1986) que apontam diferenças entre esses conceitos. Analisando o setor de enfermagem, a autora observou que os papéis de chefe e educador são assumidos pelo profissional em decorrência de imposições legais e hierárquicas, e que, nem sempre, o papel de líder é assumido, pois nem todos se sentem competentes para exercê-lo.

Portanto, há autores que diferenciam os conceitos de chefia/gerência e liderança. De fato, a chefia/gerência refere-se a uma atribuição de 
poder organizacional e a liderança corresponderia a uma atribuição de poder concedida pelos seguidores. Contudo, no presente estudo, não será feita tal distinção porque serão pesquisados os estilos de liderança das pessoas que ocupam funções gerenciais, assumindo que, do ponto de vista organizacional, seria esperado que essas pessoas exercessem o papel de líderes.

Findada essas considerações acerca dos termos chefia e liderança, é importante conceituar liderança. Tal construto pode ser definido como: "influência nos objetivos e estratégias, influência no comprometimento e consentimento com relação aos comportamentos necessários para alcançar esses objetivos, influência na manutenção e identificação do grupo, e influência na cultura de uma organização" (Yukl, 1989, p. 253). Considerando uma perspectiva histórica, teorias de liderança seguem três abordagens principais. A abordagem de traços dominou o estudo da liderança até a década de 1940, a abordagem comportamental predominou entre as décadas 1940 1960 , e a abordagem contingencial é a estratégia dominante na atualidade (Yukl, 1989).

A teoria de liderança baseada em traços de personalidade sustentava-se na ideia central de que as qualidades pessoais diferenciavam os líderes dos não-líderes. Essa corrente ancorava-se na suposição de que a liderança é inata, o que significa que as pessoas teriam um traço de personalidade que as caracterizaria como líder ou como seguidor. Stogdill (1948) revisou 124 estudos sobre liderança e apontou que os líderes tinham alguns traços superiores aos demais indivíduos, tais como: inteligência, escolaridade, confiança, participação social e status econômico e social. Mas o próprio Stogdill já considerava a teoria sobre liderança frágil e inconclusiva, ponderando que fatores contextuais também poderiam influenciar na formação de um líder. Para o autor uma pessoa não se torna líder exclusivamente em função da posse de uma combinação de traços. O padrão de características pessoais do líder também produz relações com as características, atividades e objetivos dos seguidores (Stogdill, 1948).

Há alguns indícios de que a teoria dos traços não está totalmente ultrapassada. Pesquisas permitem concluir que alguns traços aumentam a probabilidade de sucesso como líder, mas nenhum traço é um preditor seguro da efetividade da liderança (Melo, 2004). Estudos mais recentes mostram que a conscienciosidade - um atributo da personalidade - compõe as competências pessoais que contribuem para a resolução de conflitos na equipe, que é uma das principais atribuições de um líder (Caetano, 2007).

A segunda corrente focaliza as teorias comportamentais que, em contraste à teoria dos traços, propõem que a liderança pode ser ensinada, ou seja, pessoas podem ser transformadas em líderes ao invés de nascerem líderes. Nessa abordagem, a liderança passa a ser 
explorada como um estilo com foco na natureza do trabalho gerencial e numa classificação das diferentes funções, práticas, papéis e comportamentos do líder. A partir dessa teoria foram desenvolvidos treinamentos de líderes com pesquisas que objetivavam verificar se as pessoas treinadas revelavam ou não maior eficiência (Stogdill, 1974; Bryman, 1986).

Ainda são bastante frequentes os cursos para formação de liderança que têm enfoque comportamental. Porém, essa teoria é limitada na medida em que considera pouco o contexto no qual o líder está inserido e supervaloriza o treinamento de competências de forma padronizada, quando a necessidade de cada líder pode ser diferente.

Por fim, a terceira corrente teórica, a da liderança contingencial ou situacional surgiu a partir de 1960 em função da incapacidade das abordagens anteriores de explicar os diferentes aspectos do comportamento do líder (Pierce \& Newstrom, 1995). Vários modelos tentaram identificar quando o comportamento dos líderes era mais eficiente e alguns alcançaram maior reconhecimento (Bass, 1985; Bryman, 1996). Cinco modelos podem ser considerados os principais: (i) o de Fiedler (1964): a eficácia do desempenho do grupo depende da adequação entre o estilo do líder e o grau de controle que a situação Ihe proporciona; (ii) o de Hersey e Blanchard (1982): o foco são os liderados, a liderança bem-sucedida é alcançada pela escolha do estilo adequado que é contingente ao nível de prontidão dos liderados; (iii) o da troca entre líder-membro: por causa das pressões do tempo, os líderes estabelecem um relacionamento especial com um pequeno grupo de liderados, que constituem o grupo de dentro, os demais, formam o grupo de fora; (iv) o dos objetivos compartilhados: a teoria da meta e do caminho, argumenta que a função do líder é ajudar os subordinados no alcance de suas metas; e (v) o da liderança participativa: o modelo de participação e liderança (Vroom \& Yetton, 1973) relaciona o comportamento de liderança com a participação no processo decisório.

As teorias contingenciais apoiam-se, portanto, na ideia central de que a emergência e a manutenção de um líder eficaz relacionam-se a aspectos do meio ambiente no qual o líder está inserido. Assim, a liderança compreende, sobretudo, "um relacionamento, um processo mútuo de ligação entre líder e seguidor e tal processo envolve um relacionamento de influência em duplo sentido, orientado principalmente para o atendimento de objetivos e expectativas mútuas" (Davel \& Machado, 2001, p.110).

Além das três teorias clássicas sobre liderança - teorias do traço, comportamental e contingencial - ao longo da década de 1980 e 1990, foram sendo acrescentadas no corpo conceitual da área as questões culturais e identificatórias (Yukl, 1989). Fatores macroorganizacionais passaram a ser considerados e o conceito de liderança compreendido como processual e circunstancial, datado no 
tempo e dependente do reconhecimento que alcançará nas pessoas (Davel \& Machado, 2001). Nesse sentido, o processo de percepção dos liderados em relação ao líder poderia influenciar no comportamento dos indivíduos na equipe de trabalho (Santos \& Castro, 2008).

Também vale considerar entre as principais teorias processuais a da liderança transformacional, introduzida por Burns (1978) e aprofundada por Bass e Avolio (1995). O estilo de liderança transformacional se contrapõe ao estilo de liderança transacional, associado a uma relação de reciprocidade entre líderes e liderados, em que as metas e objetivos são apresentados e seu atingimento por parte da equipe é recompensado pelo líder (Burns, 1978). A liderança transformacional, de forma antagônica, diz respeito a uma visão de longo prazo, voltada para o desenvolvimento de esforços para levar os liderados a obterem maior motivação, satisfação, autocontrole e senso de realização, com treinamento adequado e desafios para a busca de melhores resultados, implicando confiança, facilitação e não o controle direto (Oliveira, Ferreira, \& Mourão, 2013). De acordo com Bass, Avolio e Atwater (1996), o estilo de liderança transformacional pode ser caracterizado por quatro componentes, a saber: consideração individual, estimulação intelectual, inspiração e carisma. Assim, o estilo transformacional considera que o líder é um agente de transformação de sua equipe, provocando autoconfiança e mudanças positivas nos liderados.

Além dessas teorias, há que se considerarem também alguns princípios teóricos sobre a temática da liderança, como os apontados por Mintzberg (1998), Taylor (2004) e Hargreaves (2007). Mintzberg (1998) discute os efeitos da atuação do líder em equipes baseadas em conhecimento, considerando que este público responde à inspiração e não à supervisão. Já Taylor (2004) discute os processos de liderança necessários para a retenção de talentos em organizações do conhecimento, apontando que a retenção de talentos no contexto da liderança garante a competitividade e o desempenho organizacional. Por fim, Hargreaves (2007) considera que a liderança sustentável deve ser incentivada na sociedade do conhecimento porque ela promove uma aprendizagem voltada a fomentar mudanças sociais positivas, conectando passado e futuro (Lopes \& Fialho, 2014). Para além desses princípios teóricos, a pesquisa qualitativa realizada por Hansson e Monsted (2008) também merece destaque uma vez que os autores discutem o poder no contexto de equipes atuantes em organizações sociais complexas e abertas, resgatando a visão weberiana da liderança carismática, considerando que o poder dos líderes surgiria da interação e do diálogo.

Como conclusão, considera-se que as teorias de liderança passaram por diferentes olhares, não necessariamente opostos e possivelmente complementares, entre as principais correntes. A liderança seria, 
portanto, um fenômeno social complexo que decorreria de algumas características dos líderes, dos comportamentos apresentados por eles e também de condições situacionais, sobretudo, a interação com subordinados (Davel \& Machado, 2001) e variáveis situacionais como os valores organizacionais (Gosendo \& Torres, 2010).

Essa apresentação dos conceitos de liderança já evidencia que poderse-ia esperar de lideranças ativas uma atuação em termos do incentivo à aplicação do trabalho daquilo que foi aprendido em eventos instrucionais (impacto de treinamento) como também um suporte à transferência das novas habilidades e atitudes aprendidas em tais eventos. Assim, essas variáveis são apresentadas a seguir.

\subsection{Impacto de treinamento}

A área de treinamento é considerada um subsistema da área de gestão de pessoas e, por sua vez, esse subsistema estaria dividido em três componentes que são interdependentes entre si, a saber: avaliação de necessidade de capacitação, planejamento e execução do treinamento e avaliação do resultado das ações de capacitação. $O$ impacto do treinamento é um dos níveis de resultados que são mensurados na avaliação de resultados de treinamento. A literatura da área aponta que o componente de avaliação tem recebido cada vez mais atenção dos pesquisadores e profissionais da área, uma vez que com o investimento crescente em treinamento, as organizações também demonstram maior interesse em conhecer os resultados obtidos com o mesmo (Aguinis \& Kraiger, 2009; Borges-Andrade et al., 2013; Griffin, 2012).

A avaliação de treinamento diz respeito, portanto, a uma ação sistemática de coleta de informações para viabilizar a emissão de um julgamento sobre a efetividade de TD\&E nas organizações (BorgesAndrade, 2002). Atualmente, o desenvolvimento tecnológico fornece uma série de possibilidades às organizações para identificar fatores ambientais que restringem ou facilitam a melhora de desempenho dos treinados (Pilati, 2006). Além disso, há uma preocupação crescente em identificar o retorno financeiro das ações de treinamento, e de outros resultados para as organizações e para a sociedade (Mourão \& Borges-Andrade, 2013).

A avaliação de treinamento pode ser formativa ou somativa. A primeira permite colher os dados durante todo o processo de desenvolvimento do sistema instrucional e busca obter informações que validem e identifiquem as correções a serem efetuadas, enquanto a avaliação somativa tem como objetivo avaliar um programa já desenvolvido (Borges-Andrade, 2006).

O modelo de Kirkpatrick (1976) é um modelo somativo de avaliação de TD\&E e é o mais conhecido e utilizado (Aguinis \& Kraiger, 2009; Salas \& Cannon-Bowers, 2001). De acordo com esse modelo, são 
quatro os níveis de resultado de ações de treinamento: reações, aprendizagem, comportamento e resultados. O terceiro e quarto níveis dizem respeito, respectivamente, ao impacto do treinamento no desempenho individual (comportamento) e nos indicadores organizacionais (resultados). No presente estudo, o foco estará no terceiro nível, isto é, o impacto do treinamento no comportamento dos indivíduos.

O impacto do treinamento no trabalho no nível individual diz respeito à transferência positiva da aprendizagem em ações de treinamento para o ambiente de trabalho, refletindo em uma melhoria de desempenho em ações direta ou indiretamente relacionadas ao treinamento (Abbad, 1999). Considerando-se tal conceito, seria de se esperar que todos os treinamentos realizados tivessem impacto na melhoria de desempenho de seus participantes, pois não se justificaria as organizações realizarem investimentos em eventos instrucionais se elas não esperassem algum retorno positivo dos mesmos.

Para investigar os resultados neste nível, Abbad propôs um modelo que incluiu quatro grupos de variáveis explicativas, a saber: características do treinamento, características da clientela, suporte organizacional e suporte à transferência. Os resultados da pesquisa da autora mostram a importância das variáveis de suporte organizacional, suporte à transferência e características da clientela na explicação dos resultados do treinamento. A autora concluiu que os efeitos do treinamento no desempenho e nas atitudes dos participantes dependem de um ambiente organizacional propício ao uso das novas habilidades, com destaque para o poder de predição do suporte psicossocial (apoio dos chefes e colegas ao uso de novas competências).

Dezenas de estudos nacionais seguiram-se ao de Abbad (1999) e mostraram resultados que confirmam a relação entre impacto de treinamento e suporte psicossocial. Em confirmação a esses resultados, Zerbini e Abbad (2010) publicaram uma revisão das pesquisas nacionais que indica o suporte psicossocial (gerencial e social) como a principal variável explicativa de impacto do treinamento no trabalho. Esses resultados mostram que o suporte da chefia e dos colegas pode influenciar diretamente o impacto do treinamento.

Como outro indicador da possível relação dos estilos de liderança e o impacto do treinamento no trabalho, vale considerar o estudo de Azevedo (2006) sobre a relação entre as bases de poder empregadas pelo líder e o impacto do treinamento no trabalho. O autor encontrou como preditores de impacto no desempenho de controle de pessoas e processos e reporte ao superior imediato: comprometimento com a organização, bases de poder de coerção (relação negativa) e recompensa. Assim, de acordo com o estudo de Azevedo (2006), 
superiores que adotam a base de poder coercitivo influenciariam negativamente no desempenho de seus subordinados após uma ação de treinamento. A próxima seção detalha o conceito de suporte à transferência.

\subsection{Suporte psicossocial}

De acordo com Abbad et al. (2012), suporte à transferência exprime a opinião do participante de programas de treinamento sobre o apoio ambiental à aplicação eficaz, no trabalho, das habilidades adquiridas por meio de treinamentos. A variável compreende duas dimensões suporte psicossocial e suporte material. O primeiro avalia o apoio gerencial, dos colegas e da organização à aplicação de novas aprendizagens no trabalho. Compreende desde as oportunidades para praticar novas habilidades, quanto 0 acesso às informações necessárias à aplicação dos novos conhecimentos e as reações positivas de colegas ou superiores hierárquicos diante das tentativas de aplicação das novas habilidades aprendidas em treinamentos no trabalho. Já o fator suporte material refere-se à opinião dos participantes sobre a adequação do ambiente físico, bem como a qualidade, a quantidade e a disponibilidade de recursos materiais e financeiros necessários à aplicação no trabalho dos novos conhecimentos e habilidades aprendidos.

Nos estudos nacionais, Zerbini e Abbad (2010) confirmam a preponderância do contexto e, especialmente do suporte à transferência, como principal preditor do impacto do treinamento. Nos estudos estrangeiros, vários estudos que podem ser sintetizados em duas metanálises recentes confirmam tal resultado. A metanálise de Blume, Ford, Baldwin e Huang (2010), contemplando 89 estudos, aponta para relações entre transferência de treinamento e diversas variáveis preditivas referentes a variáveis ligadas a características da clientela, suporte à transferência características dos treinamentos. Os autores ressaltam o relacionamento positivo entre transferência de treinamento e habilidades cognitivas, conscienciosidade, motivação para aprender e suporte à transferência. De forma semelhante, a metanálise de Laine e Gegenfurtner (2013), a partir de um trabalho compreendendo 17 estudos, aponta para o valor preditivo de diferentes dimensões de orientação individual sobre transferência de treinamento. Os resultados mostraram que a orientação individual para o domínio de objetivos e a orientação a para o alcance de objetivos de desempenho relacionam-se positivamente com a transferência de treinamento, enquanto a orientação individual de esquiva em relação aos objetivos de desempenho relaciona-se negativamente.

Considerando que, tanto na literatura nacional quanto na estrangeira, o suporte à transferência é apresentado como uma das variáveis mais 
fortemente associadas ao impacto do treinamento no trabalho, o suporte foi incluído neste estudo como variável controle. O modelo de pesquisa apresentado na próxima seção mostra as relações que foram hipotetizadas para o presente estudo.

\section{0 modelo de pesquisa, hipótese e variáveis}

Considerando a revisão de literatura previamente apresentada e uma busca feita em bases de periódicos nacionais e estrangeiros, não se encontrou nenhum estudo relacionando a liderança ao impacto do treinamento no trabalho, embora haja sinalizações de que o estilo gerencial pode estar relacionado aos resultados do treinamento, uma vez que a variável que mais prediz o impacto do treinamento no trabalho é o suporte psicossocial, isto é, o apoio que os chefes e colegas oferecem aos treinandos para aplicarem no trabalho aquilo que aprenderam (Abbad, 1999; Aguinis \& Kraiger, 2009; Salas \& Cannon-Bowers, 2001; Zerbini \& Abbad, 2010). Porém, será que a percepção que o subordinado tem do estilo de atuação do seu líder influencia no impacto do treinamento no trabalho?

No que diz respeito à variável estilos de liderança, considerou-se no presente estudo o Modelo do Grid Gerencial (Blake \& Mouton, 1964), baseado em uma matriz que avalia a posição de cada líder em dois eixos: orientação para a produção e orientação para as pessoas. A hipótese estabelecida para o estudo foi: A percepção do estilo gerencial da chefia e o suporte à transferência atuam como variáveis preditoras da percepção de impacto do treinamento no trabalho, sendo que aqueles que percebem em sua chefia maior preocupação com a produção e com as pessoas e também maior suporte à transferência apresentarão grau mais elevado de impacto do treinamento no trabalho.

Em relação às variáveis que compõem este modelo, são apresentadas a seguir as definições constitutivas e as definições operacionais das variáveis Estilo Gerencial, Suporte Organizacional e Impacto do Treinamento no trabalho dos liderados (Tabela 1). Essas definições são fundamentais para a compreensão das próximas seções deste artigo, especialmente, para a do Método e a de Resultados.

Tabela 1.

Definições constitutiva e operacional das variáveis

\section{Definição Constitutiva}

$\begin{array}{cl}\text { Estilo } & \text { Forma de atuar dos } \\ \text { Gerencial } & \text { gerentes considerando } \\ \text { (variável } & \text { duas dimensões }\end{array}$

Definição Operacional Estilos de liderança medidos a partir da Escala de Percepção de Estilo Gerencial - EPEG 


\begin{tabular}{|c|c|c|}
\hline antecedente) & $\begin{array}{l}\text { básicas, preocupação } \\
\text { com a produção e } \\
\text { preocupação com as } \\
\text { pessoas, com base no } \\
\text { Grid Gerencial } \\
\text { desenvolvido por } \\
\text { Blake e Mouton } \\
(1964) .\end{array}$ & $\begin{array}{l}\text { (Mourão \& Faiad, 2013) que } \\
\text { contém } 13 \text { itens, com respostas } \\
\text { que variam de } 1 \text { (discordo } \\
\text { totalmente) a } 9 \text { (concordo } \\
\text { totalmente) e dois fatores: foco } \\
\text { na produção e foco nas } \\
\text { pessoas. Os itens dizem } \\
\text { respeito à percepção que os } \\
\text { subordinados têm acerca de } \\
\text { ações cotidianas do chefe. São } \\
\text { exemplos: "Meu(minha) atual } \\
\text { chefe estabelece metas claras } \\
\text { para os funcionários } \\
\text { cumprirem"; "Meu(minha) atual } \\
\text { chefe faz reuniões de trabalho } \\
\text { para falar sobre o } \\
\text { desempenho"; "Meu(minha) } \\
\text { atual chefe busca atender as } \\
\text { necessidades pessoais dos } \\
\text { empregados". }\end{array}$ \\
\hline $\begin{array}{l}\text { Impacto do } \\
\text { Treinamento } \\
\text { no trabalho } \\
\text { (variável } \\
\text { consequente) }\end{array}$ & $\begin{array}{l}\text { O impacto do } \\
\text { treinamento no } \\
\text { trabalho diz respeito à } \\
\text { transferência positiva } \\
\text { da aprendizagem em } \\
\text { ações de treinamento } \\
\text { para o ambiente de } \\
\text { trabalho, refletindo em } \\
\text { uma melhoria de } \\
\text { desempenho em ações } \\
\text { direta ou } \\
\text { indiretamente } \\
\text { relacionadas ao } \\
\text { treinamento (Abbad, } \\
\text { 1999). }\end{array}$ & $\begin{array}{l}\text { Impacto do treinamento no } \\
\text { trabalho mensurado a partir de } \\
\text { mudanças no comportamento } \\
\text { individual após a participação } \\
\text { em treinamentos, mensurados } \\
\text { por meio de uma escala } \\
\text { unifatorial de } 10 \text { itens, } \\
\text { resultante da análise fatorial } \\
\text { confirmatória realizada por } \\
\text { Pilati e Abbad (2005) e que } \\
\text { varia de } 1 \text { a } 5 . \text { São exemplos } \\
\text { de item: "Após a participação } \\
\text { no curso, tenho sugerido, com } \\
\text { mais frequência, mudanças na } \\
\text { rotina do trabalho"; "Utilizo, } \\
\text { com frequência, em meu } \\
\text { trabalho atual, o que foi } \\
\text { ensinado no curso". }\end{array}$ \\
\hline $\begin{array}{c}\text { Suporte à } \\
\text { Transferência } \\
\text { (variável } \\
\text { controle) }\end{array}$ & $\begin{array}{l}\text { Suporte à } \\
\text { Transferência avalia o } \\
\text { apoio recebido pelo } \\
\text { egresso do } \\
\text { treinamento para } \\
\text { aplicar, no trabalho, }\end{array}$ & $\begin{array}{l}\text { Suporte oferecido pela chefia e } \\
\text { pela organização, considerando } \\
\text { duas dimensões: Suporte } \\
\text { Psicossocial e o Suporte } \\
\text { Material à Transferência de } \\
\text { Treinamento, medidos por meio }\end{array}$ \\
\hline
\end{tabular}


as novas habilidades adquiridas nesses eventos instrucionais. (Abbad et al., 2012). de uma escala de 22 itens (Abbad et al., 2012), que varia de 1 a 5 . São exemplos de item: "Os obstáculos e dificuldades associados à aplicação das novas habilidades que adquiri no treinamento são identificados e removidos pelo meu chefe" "As ferramentas de trabalho (micros, máquinas e similares) são de qualidade compatível com o uso das novas habilidades aprendidas no curso".

\section{Método}

Considerando o objetivo e o modelo da pesquisa, as variáveis e a hipótese estabelecidas, apresenta-se a seguir o método definido para este estudo. Para melhor compreensão dos aspectos metodológicos, a seção foi dividida em três subseções, nomeadamente: participantes; instrumentos; procedimentos de coleta e de análise de dados - as quais são apresentadas na sequência.

\subsection{Participantes}

A presente pesquisa foi realizada por meio de um estudo de levantamento amostral em uma instituição privada do município de Magé no Estado do Rio de Janeiro. A amostra final foi de 264 empregados de uma indústria de refrigerantes. Como a pesquisa possui o impacto do treinamento no trabalho como variável dependente, a mesma adotou como critério de inclusão na amostra, funcionários que tinham participado de pelo menos uma ação de capacitação no período entre três e seis meses antes da coleta de dados.

Os treinamentos que foram alvo desta pesquisa foram divididos nos seguintes temas: meio ambiente, liderança, trabalho em equipe, motivação e comunicação. Os cursos derivaram de pedido dos líderes, exceto o de meio ambiente que é uma obrigação legal a ser cumprida pela empresa. Este último tem foco em reciclagem de resíduos, cumprimento das normas da ISO 9001 e na mudança de cultura em relação à preservação ambiental. O tempo médio de duração dos cursos foi de 20 horas. A maior parte dos cursos (88\%) foi realizada com instrutores da própria empresa. O tempo médio transcorrido desde o término do treinamento até o momento da avaliação do seu 
impacto foi de 4,6 meses $(D P=1,37)$ e a aprendizagem média declarada pelos participantes foi de 7,71 ( $D P=2,04)$, considerando uma escala que variava de zero a dez. A mensuração do impacto do treinamento foi feita por medida de autoavaliação, que consistia em um questionário, composto por 10 itens, cuja análise fatorial confirmatória foi apresentada por Pilati e Abbad (2005).

A descrição da amostra pesquisada aponta para um perfil no qual $55,4 \%$ dos respondentes eram do sexo feminino; sendo que $75,7 \%$ atuavam no setor de produção e $24,3 \%$ se dividiam entre os setores administrativo/financeiro, transporte, limpeza, logística, obras e comercial. A escolaridade dos participantes era predominantemente de pessoas com ensino médio $(51,1 \%)$, embora seja alto o percentual de colaboradores com ensino fundamental $(45,4 \%)$ e baixo o de colaboradores graduados $(3,5 \%)$.

A média de idade dos participantes foi de 31,6 anos $(D P=9,57)$ e o tempo médio de trabalho na empresa de 4,2 anos ( $D P=3,72$ ), indicando considerável rotatividade de pessoal na fábrica pesquisada. O salário médio foi de $R \$ 716,60$, $(D P=R \$ 268,40)$, situando-se, portanto, pouco acima do valor do salário mínimo do ano de 2012 que era de $\mathrm{R} \$ 622,00$.

\subsection{Instrumentos}

Os instrumentos utilizados nesta pesquisa foram: a escala de impacto de treinamento no trabalho (Pilati \& Abbad, 2005); a escala de avaliação de lideranças (Mourão \& Faiad, 2013); e a escala de suporte à transferência (Abbad et al., 2012). A primeira contém 10 itens e estrutura unifatorial, com escala tipo Likert de cinco pontos ( $1=$ discordo fortemente a $5=$ concordo fortemente), com altos coeficientes de fidedignidade (Alfa de Cronbach $=0,90 / 0,92$ no estudo original e atual). A escala de estilo gerencial possui 13 itens associados a uma escala de concordância ( 1 = discordo fortemente a 9 = concordo fortemente), com estrutura bifatorial, classificando os estilos gerenciais a partir da grade de Blake e Mouton (1964). Os fatores "preocupação com a produção" e "preocupação com as pessoas" obtiveram Alpha de Cronbach de 0,90/0,93 e 0,84/0,90, respectivamente no estudo original e na pesquisa atual.

Por fim, a escala de suporte à transferência possui 22 itens distribuídos em dois fatores: suporte material e suporte psicossocial. Ela também é associada a uma escala tipo Likert ( $1=$ Nunca e $5=$ Sempre), com bons indicadores de fidedignidade: suporte material com 0,91/0,86 no estudo original e no atual; e suporte psicossocial com 0,86 em ambos os estudos.

\subsection{Procedimentos de coleta e análise de dados}


O projeto de pesquisa foi previamente aprovado por um Comitê de Ética e todos os participantes assinaram o Termo de Consentimento Livre e Esclarecido (TCLE), tendo resguardado o direito de sigilo das informações prestadas. Como o objetivo do estudo era verificar se a percepção do estilo de liderança dos chefes influencia no impacto do treinamento no desempenho dos subordinados, tendo o suporte à transferência como variável controle, a aplicação do questionário precisava ser feita após a realização da capacitação, para que fosse possível medir seu efeito. Inicialmente foi solicitada autorização para a realização da pesquisa aos representantes da empresa. Em seguida, a pesquisadora responsável convidou individualmente os funcionários a participarem da pesquisa, sendo esclarecido o objetivo do estudo e informado o anonimato das respostas individuais. A aplicação foi feita a partir de um instrumento único, contendo as escalas de suporte organizacional, percepção de estilo de liderança e impacto do treinamento no trabalho, além das questões para caracterização da amostra. As escalas incluídas no questionário tinham natureza autoaplicável e o processo de coleta de dados foi individual para garantir maior liberdade no preenchimento do questionário que foi aplicado presencialmente, com uso de papel e lápis.

Em relação aos procedimentos de análise de dados, foi utilizado software SPSS, versão 21.0. As análises estatísticas contemplaram desde a limpeza do banco de dados até as análises inferenciais relativas ao teste das hipóteses, conforme será descrito na seção de Resultados.

\section{Resultados}

Conforme descrito no Método, na primeira etapa da análise foram avaliados os dados omissos, que foram inferiores a $1 \%$ e sem um padrão regular de distribuição pelas variáveis. Foram também examinadas as distribuições univariadas e bivariadas por meio de método gráfico (boxplot) e numérico (medidas de simetria) com o objetivo de avaliar normalidade, homogeneidade de variância e a presença de dados extremos univariados. Foram identificados 6 casos de valores extremos univariados e 18 casos univariados pouco influentes. Os primeiros foram excluídos da amostra e os últimos mantidos. Para a análise de outliers multivariados, adotou-se 0 parâmetro da Distância Mahalanobis, tendo sido identificados 10 casos com distância acima desses parâmetros, que foram excluídos de todas as análises. Assim, a amostra inicial continha 280 questionários e após a retirada dos outliers (uni e multivariados) obteve-se um total de 264 questionários válidos.

o critério numérico utilizado para avaliar a necessidade de transformações nas variáveis foi ancorado na simetria, indicando 
necessidade de transformação sempre que o escore $Z$ para simetria (simetria/erro padrão de medida da simetria) foi maior que 1,96 (Hair, Black, Babin, Anderson, \& Tatham, 2009; Tabachnick \& Fidell, 2007). Tal critério sugeria transformações nas variáveis relativas ao estilo de liderança e ao impacto do treinamento no trabalho. Foram feitas as transformações e realizadas as análises estatísticas com e sem as mesmas. Como as diferenças foram muito pequenas, optouse por trabalhar com as variáveis sem transformação em todas as análises estatísticas.

Para a regressão também foram avaliadas, além da normalidade, a homogeneidade de variância, a multicolinearidade e a análise de resíduos. Encontrou-se alta correlação entre a preocupação com a produção e a preocupação com as pessoas $(r=0,83 ; p<0,001)$ e entre suporte psicossocial e suporte material $(r=0,67 ; p<0,001)$. Contudo, o teste de colinearidade não apresentou valores de VIF acima de cinco e nem valores de tolerância baixo de 0,1 , e o condition index indicou que tais variáveis não apresentariam problemas de colinearidade se ficassem juntas como variáveis independentes no mesmo modelo.

A hipótese desta pesquisa previa que a percepção do estilo gerencial da chefia e o suporte à transferência seriam variáveis preditoras da percepção de impacto do treinamento no trabalho, sendo que aqueles que percebem em sua chefia maior preocupação com a produção e com as pessoas e também maior suporte à transferência apresentariam grau mais elevado de impacto do treinamento no trabalho.

As correlações de Pearson apontaram relações positivas e significativas entre todas as variáveis do modelo (Tabela 2). À exceção da correlação entre suporte material e liderança preocupada com a produção $(r=0,46, p<0,01)$, todas as demais tiveram magnitudes consideradas elevadas (acima de 0,50), segundo a classificação de Miles e Shevlin (2001).

Tabela 2.

Correlações de Pearson entre as variáveis do modelo

\begin{tabular}{lcccc}
\hline & $\begin{array}{c}\text { Impacto } \\
\text { do } \\
\text { Treiname } \\
\text { nto }\end{array}$ & $\begin{array}{c}\text { Liderança } \\
\text { preocup } \\
\text { pessoas }\end{array}$ & $\begin{array}{c}\text { Suporte } \\
\text { psicossoci } \\
\text { al }\end{array}$ & $\begin{array}{c}\text { Suporte } \\
\text { material }\end{array}$ \\
\hline $\begin{array}{l}\text { Liderança preocupada com } \\
\text { produção } \\
\text { Liderança preocupada com }\end{array}$ & $0,66^{*}$ & $0,83^{*}$ & $0,59 *$ & $0,46^{*}$ \\
$\begin{array}{l}\text { pessoas } \\
\text { Suporte psicossocial }\end{array}$ & $0,62^{*}$ & & $0,66 *$ & $0,52^{*}$ \\
Suporte material & $0,68^{*}$ & & & \\
\hline
\end{tabular}


$* p<0,01$

Foi também realizada uma regressão hierárquica considerando dois blocos, o primeiro continha as variáveis de estilo de liderança (preocupação com a produção e preocupação com as pessoas) e o segundo bloco com a variável suporte à transferência (suporte material e psicossocial). A Tabela 3 mostra o resultado obtido na regressão hierárquica.

Tabela 3.

Resultado da regressão hierárquica para o impacto do treinamento no trabalho

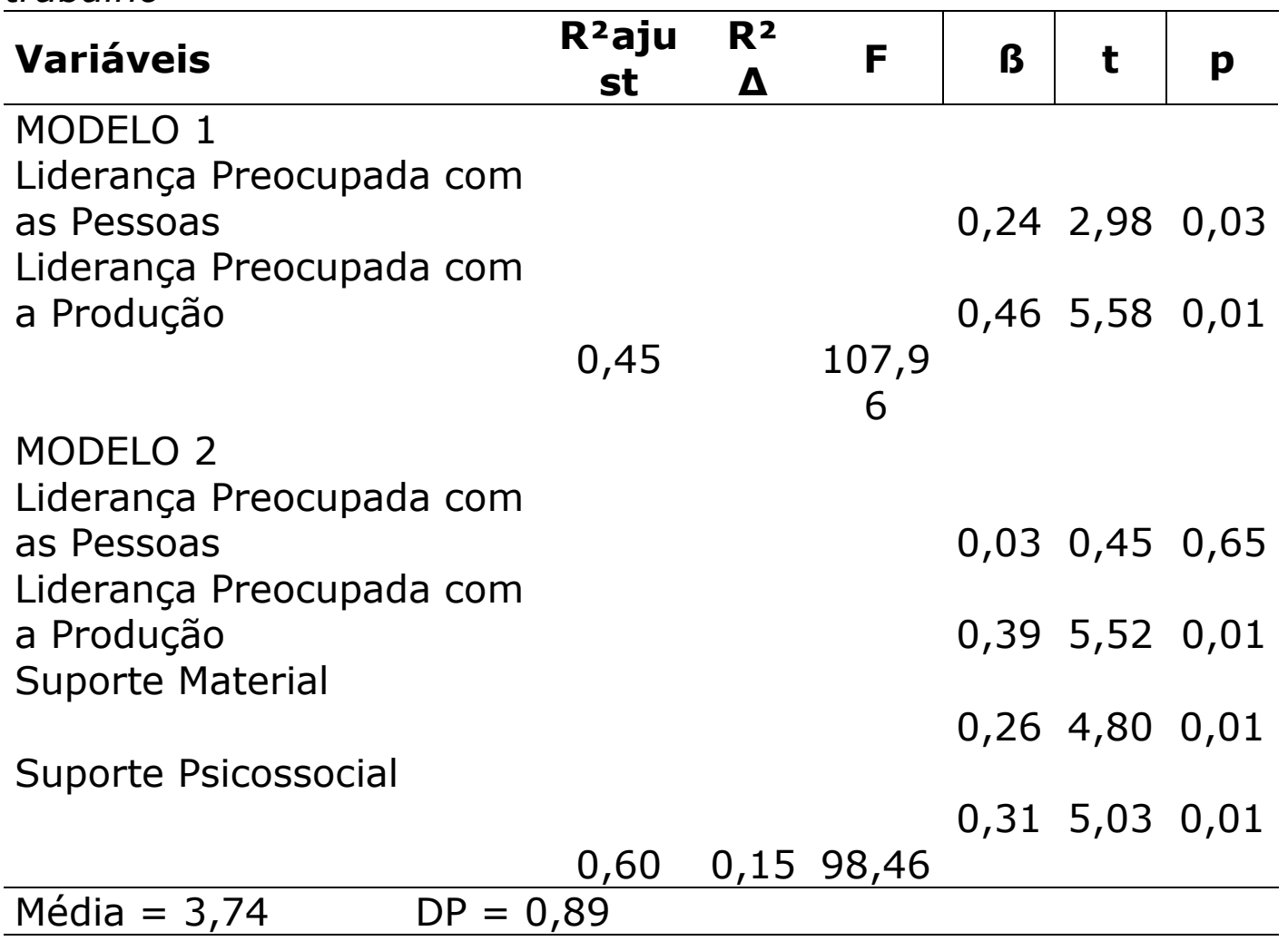

A análise dos resultados da regressão hierárquica mostra a comprovação parcial da hipótese, na medida em que o estilo de liderança preocupado com a produção figura como preditor do impacto do treinamento no trabalho em ambos os modelos, mas o estilo preocupado com as pessoas não. Vale observar que, com a entrada da variável controle suporte à transferência (material e psicossocial), obtém-se um acréscimo de $15 \%$ no poder explicativo do modelo $\left(R^{2} \Delta=0,15 ; F=98,46 ; p<0,01\right)$, mas o estilo de liderança preocupado com as pessoas deixa de figurar como preditora do impacto do treinamento. A discussão desses resultados é apresentada na próxima seção à luz da literatura revisitada. 


\section{Discussão}

A hipótese de pesquisa previa que a percepção do estilo de liderança e o suporte à transferência atuariam como variáveis preditoras da percepção de impacto do treinamento no trabalho, sendo que aqueles que percebem em sua chefia maior preocupação com a produção e com as pessoas e também maior suporte à transferência apresentariam grau mais elevado de impacto do treinamento. Essa hipótese foi apenas parcialmente confirmada, uma vez que a liderança preocupada com a produção foi preditora do referido impacto, enquanto a preocupação da liderança com as pessoas, ainda que tenha tido correlação positiva e significativa com o impacto do treinamento no trabalho, não permaneceu no modelo final obtido com a análise de regressão.

$O$ ineditismo desta pesquisa reside exatamente na relação que foi encontrada entre o estilo de liderança voltado para a produção no desempenho no trabalho e o impacto do treinamento na performance individual, tendo como variável controle o suporte do chefe, dos pares e das condições materiais. A metanálise apresentada por Blume et al. (2010) confirma as relações entre impacto de treinamento e o suporte de pares e supervisores.

Esses resultados parecem estar em consonância com a metanálise apresentada por Laine e Gegenfurtner (2013) que mostra que a orientação individual para o alcance de objetivos de desempenho está positivamente relacionada ao impacto de treinamento. Nesse sentido, as lideranças com estilo mais voltado para a produção alimentariam essa orientação individual para 0 alcance de objetivos de desempenho, explicando a sua relação positiva com o impacto do treinamento no trabalho.

O fato de que a liderança, voltada para a produção, associada a melhores resultados de impacto do treinamento no trabalho, traz reflexões acerca dos achados de Kahn e Katz (1953, citados por Jesuíno, 2005) que concluíram que os líderes dos grupos altamente produtivos eram mais orientados para as pessoas do que para a tarefa ou para a organização. O resultado desta pesquisa é que grupos sob liderança voltada para a produção, que recebem suporte no trabalho, tenderão a apresentar maior impacto do treinamento em seus desempenhos. Nesse sentido, seria de se esperar que os resultados de impacto do treinamento estivessem associados à produção, uma vez que eles influenciam desempenhos individuais no trabalho.

Mas também é preciso considerar que a pesquisa foi realizada em um ambiente fabril, em que predomina uma percepção de que a preocupação com a produção é mais elevada do que a preocupação 
com as pessoas (As-Sadeq \& Khoury, 2006; Emery \& Barker, 2007; Gosendo \& Torres, 2010). Destarte, seria importante reproduzir a mesma pesquisa em outros contextos para verificar se o estilo de liderança voltado para a produção continua se mantendo como preditor do impacto do treinamento no trabalho.

Vale considerar, como uma limitação da empresa pesquisada, o fato de os treinamentos avaliados não estarem alinhados à estratégia da organização. Lamentavelmente, a referida empresa não tem um plano de carreira claramente estabelecido em que os empregados se inscrevem em cursos de capacitação que Ihe permitiram galgar novos postos. Em geral, a indicação para os cursos é feita pelas chefias e a organização espera que os treinamentos realizados resultem em melhorias de desempenho e maior segurança no trabalho, sendo que os chefes participam de alguns treinamentos e de outros não. Se houvesse tal alinhamento da área de treinamento com a estratégia da empresa, possivelmente o poder de predição do estilo de liderança voltada para a produção poderia ser maior, bem como o efeito do suporte à transferência, pois, neste caso, seria esperada maior participação das chefias.

Ainda termos de discussão com a literatura da área, o estudo de Misumi e Seki (1971) mostrou que em equipes com elevada motivação, os supervisores que obtinham os melhores resultados eram aqueles do tipo 9,9 no Grid Gerencial, isto é, os que tinham simultaneamente alta preocupação com a produção e alta preocupação com as pessoas. No mesmo estudo, confirmando os achados de Blake e Mouton (1964), os subordinados apresentaram maior satisfação com os líderes altamente preocupados com as tarefas e com os relacionamentos.

Um aspecto que chama a atenção nos resultados é o fato de que os estilos de liderança, predominantes na organização, apontam líderes com baixa preocupação com as pessoas e com a produção e outros com preocupação elevada em ambos os quesitos. Essa disparidade entre os pontos de vista dos liderados também foi encontrada por Alba, Toigo e Barcellos (2010) que observaram, em seu estudo com atletas, que jogadores de uma mesma equipe, davam respostas díspares em relação a algumas dimensões da liderança.

Essa dessemelhança de opiniões mostra que não apenas a organização e as atividades influenciam o estilo de liderança, mas também a percepção tanto dos líderes como dos liderados pode influenciar neste processo. Esse achado confirma os aspectos teóricos apontados por Davel e Machado (2001) que consideram a liderança como um processo mútuo de ligação entre líder e seguidor, com influência em duplo sentido.

Por fim, cabe discutir os resultados relativos à influência do suporte à transferência sobre o impacto do treinamento. Tanto o suporte material quanto o psicossocial figuraram como preditores positivos do 
impacto do treinamento no trabalho. Este resultado confirma os achados de dezenas de estudos nacionais (Zerbini \& Abbad, 2010) e estrangeiros (Aguinis \& Kraiger, 2009; Salas \& Cannon-Bowers, 2001). De fato, o apoio da chefia e dos colegas e o suporte material fornecido aos empregados contribui para que as pessoas treinadas consigam aplicar no trabalho aquilo que aprenderam nas ações educacionais. Isso reforça a ideia de que não basta oferecer treinamento, é preciso oferecer aos empregados as condições para implementar aquilo que aprenderam (Abbad et al., 2012; BorgesAndrade et al., 2013). A próxima seção apresenta as principais conclusões deste estudo, bem como as limitações e contribuições relativas ao mesmo.

\section{Conclusões}

O objetivo deste estudo foi verificar se a percepção do estilo de liderança dos chefes influencia no impacto do treinamento no desempenho dos subordinados, tendo o suporte à transferência como variável controle. A pesquisa realizada em uma indústria fluminense de bebidas permitiu concluir que: (i) na percepção dos liderados, suas chefias estão mais preocupadas com a produção do que com as pessoas; (ii) existe correlação significativa e positiva entre a preocupação com as pessoas e o impacto do treinamento no trabalho; (iii) a percepção de liderança preocupada com a produção é preditora do impacto do treinamento no trabalho, sendo que quanto maior a preocupação da chefia com os resultados, maior o impacto do treinamento; (iv) as variáveis suporte psicossocial e o suporte material, quando pesquisadas em conjunto com as variáveis de estilo de liderança, permitem um incremento da explicação do modelo relativo ao impacto do treinamento no trabalho.

Portanto, corroborando outros achados da literatura nacional e estrangeira, os resultados da presente pesquisa permitem concluir que o comportamento do líder gera um reflexo no desempenho do grupo de trabalho. Tais achados sugerem maior investimento na qualificação gerencial, visando preparar os líderes para uma atuação integrada, contemplando ações voltadas para a tarefa e também para os relacionamentos interpessoais.

Um aspecto que as organizações também precisam prestar atenção refere-se ao suporte psicossocial e material, uma vez que ele contribui para o impacto do treinamento no trabalho. Assim, se as chefias compreenderem os objetivos da capacitação e derem suporte para a transferência de aprendizagem, os resultados os treinamentos tenderão a ser mais efetivos.

Como limitações desta pesquisa, podem ser citados o fato de a mesma ter sido feita em uma única organização e na mesma cidade, 
o que não permite a generalização dos seus resultados para outros contextos. Outra limitação é o fato de a pesquisa ter se baseado apenas em variáveis perceptuais, sendo recomendável que estudos futuros considerem também indicadores duros relativos ao impacto do treinamento no trabalho, possivelmente voltados para indicadores de desempenho.

Como uma agenda de pesquisa derivada deste estudo pode ser sugerida a ampliação do escopo, no sentido de contemplar diferentes contextos e observar as possíveis mudanças nos resultados. Além disso, também seria interessante realizar um estudo experimental, no qual um grupo de chefes seria treinado em conjunto com os seus subordinados e outro grupo teria somente os subordinados treinados. O resultado permitiria verificar em que medida a participação da chefia nos treinamentos modifica o suporte aos liderados.

\section{Referências}

Abbad, G. S. (1999). Um modelo integrado de avaliação do impacto do treinamento no trabalho - IMPACT. Tese de Doutorado nãopublicada, Universidade de Brasília, Brasília, DF, Brasil.

Abbad, G. S., Sallorenzo, L. H., Coelho, F. A. Jr., Zerbini, T., Vasconcelos, L., \& Todeschini, K. (2012). Suporte à transferência de treinamento e suporte à aprendizagem. In G. Abbad, L. Mourão, P. P. M. Meneses, T. Zerbini, J. E. BorgesAndrade, \& R. Vilas-Boas (Eds.). Medidas de avaliação em treinamento, desenvolvimento e educação: ferramentas para gestão de pessoas (pp. 244-263). Porto Alegre: Artmed.

Aguinis, H., \& Kraiger, K. (2009). Benefits of Training and Development for Individuals and Teams, Organizations, and Society. Annual Review Psychology, 60, 451-474.

Alba, G. R., Toigo, T., \& Barcellos, P. F. P. (2010). Percepção de atletas profissionais de basquetebol sobre o estilo de liderança do técnico. Revista Brasileira de Ciência do Esporte, 32(1), 143159.

As-Sadeq, H. A., \& Khoury G. C. (2006). Leadership styles in the Palestinian large-scale industrial enterprises. Journal of Management Development, 25(9), 832-849.

Azevedo, L.P.S. (2006). Comprometimento e bases de poder como preditores de impacto de treinamento no trabalho em Contact Center. Dissertação de Mestrado não-publicada, Universidade Federal de Uberlândia, Uberlândia, MG, Brasil.

Bass, B.M. (1985). Leadership and Performance beyond Expectations. New York: Free Press.

Bass, B., \& Avolio, B. (1995). Multifactor Leadership Questionnaire: Technical Report. Rewood City, CA: Mind Garden Inc. 
Bass, B. M., Avolio, B. J., \& Atwater, L. (1996). The transformational and transactional leadership of men and women. Applied Psychology: An International Review, 45, 5-34.

Blake, R., \& Mouton, J. (1964). The Managerial Grid: The Key to Leadership Excellence. Houston: Gulf Publishing Co.

Blume, B, Ford, K, Baldwin, T, \& Huang, J. (2010). Transfer of Training: A Meta-Analytic Review. Journal of Management, 36, 1065-1105.

Borges-Andrade, J. E. (2002). Desenvolvimento de medidas em avaliação de treinamento. Revista Estudos de Psicologia, 7(número especial), 31-43.

Borges-Andrade, J. E. (2006). Avaliação integrada e somativa em TD\&E. Em J. E. Borges-Andrade, G. S. Abbad, \& L. Mourão (Orgs.), Treinamento, desenvolvimento e educação em organizações e trabalho: Fundamentos para gestão de pessoas (pp. 343-358). Porto Alegre: Artmed.

Borges-Andrade, J. E., Zerbini, T., Abbad, G. \& Mourão, L. (2013): Treinamento, desenvolvimento e educação: um modelo para a sua gestão. In L. O. Borges, \& L. Mourão (Orgs.). O trabalho e as organizações: atuações a partir da Psicologia (pp. 465-496). Porto Alegre: Artmed.

Bryman, A. (1986). Leadership and Organizations. London: Routledge \& Kegan Paul.

Bryman, A. (1996). Leadership in organizations. In R. Stewart (Ed.). Handbook of Organization Studies. (pp. 276-92). London: Sage Publications.

Burns, J. M. (1978). Toward a general theory. In J. T. Wren., D. A. Hicks., \& T. L. Price (Eds.), New perspectives on leadership (pp. 3-24). Northampton, MA: Edward Elgar.

Caetano, P. F. (2007). Construção e Validação do Inventário de Competências Pessoais para o Trabalho - ICPT. Dissertação de Mestrado. Universidade de Brasília, Brasília, DF, Brasil.

Carneiro, A. (1986). Interrelaçäo dos papéis de chefe, educador e líder, desempenhados pelo enfermeiro. Revista Baiana de Enfermagem, 2(2), 58-73, 1986.

Cherian, J., \& Farouq, S. (2013). Does effective leadership style drive financial performance of banks? Analysis in the context of UAE banking sector. International Journal of Economics and Finance, 5(7), 105-114.

Davel, E., \& Machado, H. (2001). A dinâmica entre liderança e identificação: sobre a influência consentida nas organizações contemporâneas. Revista de Administração Contemporânea, 5(3), 107-126.

Emery, C.R., \& Barker, K. J. (2007). The effect of transactional and transformational Leadership Styles on the Organizational Commitment and Job Satisfaction of Customer Contact 
Personnel. Journal of Organizational Culture, Communication and Conflict, 11(1), 77-91.

Fiedler, F. E. (1964). A contigency of model of leadership effectiveness. In L. Berkowitz (Ed.). Advances in Experimental Social Psychology. (Vol. 1, pp. 149-190). New York: Academic Press.

Freitas, I. A., \& Borges-Andrade, J. E. (2004). Efeitos de Treinamento nos Desempenhos Individual e Organizacional. Revista de Administração de Empresas, 44(3) 44-56.

Garg, A. K., \& Ramjee, D. (2013). The relationship between leadership styles and employee commitment at A parastatal company in South Africa. The International Business \& Economics Research Journal (Online), 12(11), 1411-1436.

Gosendo, E. E. M., \& Torres, C. V. (2010). Influência dos valores organizacionais sobre estilos de gerenciamento em empresas de pequeno porte. Paidéia (Ribeirão Preto), 20(45), 29-38.

Griffin, R. (2012). A practitioner friendly and scientifically robust training evaluation approach. Journal of Workplace Learning, 24(6), 393-402.

Hair JR., Black, W. C., Babin, B. J., Anderson, R. E., \& Tatham, R. L. (2009). Análise multivariada de dados. $6^{a}$ ed. Porto Alegre: Bookman.

Hansson, F., \& Monsted, M. (2008). Research leadership as entrepreneurial organizing for research. Higher Education, 55(6), 651-670.

Hargreaves, A. (2007). Sustainable leadership and development in education: creating the future, conserving the past. European Journal of Education, 42(2), 223-233.

Hersey, P., \& Blanchard, K. H. (1982). Psicologia para administradores: a teoria e as técnicas da liderança situacional. (Edwino A. Royer, Trad.). São Paulo: Editora Pedagógica e Universitária.

Jesuíno, J. C. (2005). Processos de liderança (4a ed.). Lisboa: Livros Horizontes.

Kirkpatrick, D. L. (1976). Evaluation of training. In R. L. Craig (Ed.). Training and Development Handhook (pp. 18.1-18.27). New York: Mc Graw-Hill.

Laine, E, \& Gegenfurtner, A. (2013). Stability or change? Effects of training length and time lag on achievement goal orientations and transfer of training. International Journal of Educational Research. 61, 71-79.

Lopes, M. C., \& Fialho, F. A. P. (2014). Liderança no contexto da sociedade do conhecimento: uma revisão sistemática. Revista da UNIFEBE, 1(13), 1-19. 
Melo, E. A. A. (2004). Escala de avaliação do estilo gerencial (EAEG): desenvolvimento e validação. Revista Psicologia Organizações e Trabalho - rPOT, 4(2), 31-62.

Miles, J., \& Shevlin, M. (2001). Applying Regression and Correlation: a guide for students and researchers. London: Sage Publications.

Mintzberg, H. (1998). Covert leadership: notes on managing professionals. Harvard Business Review, 36(6), 140-147.

Misumi, J., \& Seki, F. (1971). Effects of Achievement Motivation on the Effectiveness of Leadership Paterns. Administrative Science Quartely, 16, 51-59.

Mourão, L., Abbad, G. S., \& Zerbini, T. (2014). Avaliação da efetividade e dos preditores de um treinamento a distância em uma instituição bancária de grande porte. Revista de Administração da USP, 49(3), 534-548.

Mourão, L., \& Borges-Andrade, J. E. (2013). Impact evaluation of T\&D at the societal level. Journal of Workplace Learning, 25, 505-520.

Mourão, L., \& Faiad, C. (2013, outubro). Validação de Escala para Mensuração do Desenvolvimento Profissional. Pôster apresentado na XV Jornada Científica da Universidade Salgado de Oliveira - Universo, Niterói - RJ.

Oliveira, R. A., Ferreira, M. C., \& Mourão, L. (2013). O fenômeno da liderança: uma revisão das principais teorias. Fragmentos de Cultura, 23(4), 587-601.

Pierce, J. L., \& Newstrom, J.W. (1995). Instructor's resource manual to accompany Leaders and the Leadership Process. Chicago: Austen Press.

Pilati, R., \& Borges-Andrade, J. E. (2004). Estudo empírico dos antecedentes de medidas de impacto do treinamento no trabalho. Psicologia: Teoria e Pesquisa, 20(1), 31-38.

Pilati, R. (2006). História e Importância de TD\&E. In J. E. BorgesAndrade, G. S. Abbad, \& L. Mourão (Orgs). Treinamento, desenvolvimento e educação em organizações e trabalho: Fundamentos para gestão de pessoas (pp. 159-176). Porto Alegre: Artmed.

Pilati, R., \& Abbad, G.S. (2005). Análise fatorial confirmatória da escala de impacto do treinamento em amplitude no trabalho. Psicologia Teoria e Pesquisa, 21(1), 43-51.

Reddin, W. J. (1970). Eficácia Gerencial. São Paulo: Atlas.

Salas, E., \& Cannon-Bowers, J.A. (2001). The science of training: a decade of progress. Annual Review Psychology, 52, 471-499.

Santos, I., \& Castro, C. B. (2008). Estilos e dimensões da liderança: iniciativa e investigação no cotidiano do trabalho de enfermagem hospitalar. Texto Contexto - Enfermagem, 17(4), 734-742. 
Stogdill, R. (1948). Fatores pessoais associadas com a liderança: um levantamento da literatura. Journal of Psychology, 25, 35-71.

Stogdill, R. (1974). Handbook of Leadership. Nova York: The Free Press.

Tabachnick, B. G., \& Fidell, L. S. (2007). Using multivariate statistics. (5th ed.). New York: HarperCollins.

Taylor, C. R. (2004). Retention leadership. $T$ and D, 58(3), 40-45.

Vargas, M. R. M. (1996). Treinamento e desenvolvimento: reflexões sobre seus métodos. Revista de Administração da Universidade de São Paulo - RAUSP, 31(2), 126-136.

Vroom, V., \& Yetton, P. (1973). Leadership and decision-making. Pittsburgh: University of Pittsburgh Press.

Wu, M. (2014). Verifying the influences of leadership styles upon organizational performances: Balance-scored card implementation as a moderator. Journal of International Management Studies, 9(1), 25-37.

Yukl, G. (1989). Liderança Gerencial: uma revisão da teoria e pesquisa. Journal of Management, 15, 251-289.

Zerbini, T., \& Abbad, G. (2010). Transferência de treinamento e Impacto do treinamento no trabalho: análise crítica da literatura. Revista Psicologia: Organizações e Trabalho, 10(2), 97-111.

\section{Endereço para correspondência \\ Neilda de Souza Oliveira da Silva}

Universidade Salgado de Oliveira

Programa de Pós-Graduação em Psicologia

Rua Marechal Deodoro, 217 - $2^{\circ}$ andar, Centro, CEP 24030-060, Niterói - RJ, Brasil Endereço eletrônico: grapete.pakera@hotmail.com

\section{Luciana Mourão}

Universidade Salgado de Oliveira

Programa de Pós-Graduação em Psicologia

Rua Marechal Deodoro, 217 - $2^{\circ}$ andar, Centro, CEP 24030-060, Niterói - RJ, Brasil

Endereço eletrônico: mourao.luciana@gmail.com

Recebido em: 06/06/2014

Reformulado em: 23/11/2014

Aceito para publicação em: 25/11/2014

\section{Notas}

* Pedagoga. Mestre em Psicologia pela Universidade Salgado de Oliveira Niterói/RJ - Brasil.

** Doutora em Psicologia. Professora do Programa de Pós-graduação da Universidade Salgado de Oliveira - Niterói/RJ - Brasil. 